\title{
Using X-ray transmission/attenuation to quantify fluid absorption in cracked concrete
}

Weiss, Jason; Geiker, Mette R.; Hansen, Kurt Kielsgaard

Published in:

International Journal of Materials and Structural Integrity

Link to article, DOI:

10.1504/ijmsi.2015.071107

Publication date:

2015

Document Version

Peer reviewed version

Link back to DTU Orbit

Citation (APA):

Weiss, J., Geiker, M. R., \& Hansen, K. K. (2015). Using X-ray transmission/attenuation to quantify fluid absorption in cracked concrete. International Journal of Materials and Structural Integrity, 9(1-3), 3-20. https://doi.org/10.1504/ijmsi.2015.071107

\section{General rights}

Copyright and moral rights for the publications made accessible in the public portal are retained by the authors and/or other copyright owners and it is a condition of accessing publications that users recognise and abide by the legal requirements associated with these rights.

- Users may download and print one copy of any publication from the public portal for the purpose of private study or research.

- You may not further distribute the material or use it for any profit-making activity or commercial gain

- You may freely distribute the URL identifying the publication in the public portal 


\title{
Using X-ray transmission/attenuation to quantify fluid absorption in cracked concrete
}

\author{
Jason Weiss* \\ Lyles School of Civil Engineering, \\ Purdue University, \\ 550 Stadium Mall Dr., \\ West Lafayette, IN 47907, USA \\ Email: wjweiss@purdue.edu \\ *Corresponding author
}

\section{Mette R. Geiker}

Department of Structural Engineering, Norwegian University of Science and Technology,

7491 Trondheim, Norway

Email: mette.geiker@ntnu.no

\section{Kurt K. Hansen}

Department of Civil Engineering, Technical University of Denmark, Building 118, Kgs., Lyngby, DK-2800, Denmark

Email: kkh@byg.dtu.dk

\begin{abstract}
Cracks can alter the rate of fluid transport in concrete. Unfortunately, however, quantitative information is lacking to provide definitive statements regarding the extent to which cracks reduce durability or long-term performance. This paper describes a study that used $\mathrm{X}$-ray transmission/attenuation to determine the influence of cracking on the absorption of fluid in concrete. Specifically, an experimental method is presented which uses a wedge splitting test to pre-crack specimens. These pre-cracked specimens were dried and ponded with water. At various times after the start of water ponding, X-ray attenuation measurements were taken using a grid of points around the crack. By repeating this measurement and comparing the change in X-ray transmission/attenuation, the ingress of the fluid could be determined by locating the position of the moisture front. An approach is presented to determine the geometry of the crack by using water absorption perimeter measurements of the wetting front in the concrete.
\end{abstract}

Keywords: absorption; concrete; cracks; ingress; X-ray.

Reference to this paper should be made as follows: Weiss, J., Geiker, M.R. and Hansen, K.K. (2015) 'Using X-ray transmission/attenuation to quantify fluid absorption in cracked concrete', Int. J. Materials and Structural Integrity, Vol. 9, Nos. 1/2/3, pp.3-20. 
Biographical notes: Jason Weiss is the Jack and Kay Hockema Professor of Civil Engineering and the Director of the Pankow Laboratory at Purdue University. He earned a BAE degree from Penn State University and an MS and a PhD degree from Northwestern University. His research interests include shrinkage, early age behaviour, cracking and moisture transport in concrete.

Mette R. Geiker is a Professor at the Norwegian University of Science and Technology (NTNU). Her research interests include structure-property relationships, porosity characterisation, cementitious materials, fresh concrete properties, property development, solid/pore-liquid interaction, durability, reinforcement corrosion and sustainability.

Kurt K. Hansen is an Associate Professor at the Department of Civil Engineering of Technical University of Denmark.

\section{Introduction and background}

The durability of a concrete structure is related to its ability to impede, or greatly reduce, the rate of fluid transport. While a great deal of research has been performed to assess the corrosion susceptibility of steel in concrete structures; the majority of previous research has been focused on describing the behaviour of undamaged (pristine) concrete, and comparatively little work has been performed to quantitatively describe how these properties change due to cracks. The effect of crack width on performance is not very well established and there are controversial findings about the role of cracking in the performance of concrete structures with some authors citing significant decreases in performance while others report that cracks have less substantial impact on overall performance.

Visible cracks are generally thought to increase penetrability. Wang et al. (1997) used splitting tensile specimens to show that cracks greater than 50 microns increase the potential for water and other aggressive agents to flow through the concrete. In a follow up study, Aldea et al. (1999) reported that high-strength concrete (designed to demonstrate low permeability) had flow rates after cracking that were nearly identical to cracked normal strength concrete. Edvardson (1999) presented an analytical model to show that the flow of water through a crack would be related to the cube of the crack width. It should be noted that these studies each describe a case in which tensile loading was used to introduce the crack in saturated concrete and the direction of the flow was primarily through the crack. The crack was also a single coalesced crack which had a uniform width throughout the thickness (i.e., the crack faces are approximately parallel). As such, the approach described by Edvardson (1999) focused primarily on comparing the flow of water into the crack and the water that exits in the crack. This assesses the flow through the crack however little information is available on the movement and accumulation of water in the cracked concrete if it is not saturated.

Other researchers have also investigated the influence of cracking on ingress flexural tests by Hansen et al. (1999a) showed higher water absorption rates due to distributed cracking in plain and fibre reinforced concrete caused by flexural loading. Hearn (1999) reported that cracking caused by tensile loading prior to a specimen reaching the peak 
load does not have a substantial influence on the transport properties. It was concluded that this may occur as a result of narrower cracks being healed by autogenous healing owing to chemical deposition in the cracks (Hearn, 1998). Similarly, Samaha and Hover (1992) did not observe any significant increases in penetrability for specimens tested in compression until the load reached approximately $75 \%$ of the peak load which may indicate that crack coalescence, rather than micro-cracking alone, may be required before substantial changes in the transport response occur. Direct tensile tests by Yang et al. (2007) indicated that absorption may be locally altered by a single crack however this may not have a substantial influence on an absorption rate measured for a large sample. Küter et al. (2005) observed that repetitive loading caused in increased chloride ingress into saturated cracks and proposed this to be due to overpressure in the crack tip near region.

In addition to previous studies that focused on cracking caused by mechanical loading, studies have been conducted to look at cracking caused by environmental loading (i.e., freezing and thawing, thermal cracking, or drying and autogenous shrinkage). While a load induced crack is generally a localised event (i.e. a discrete crack), environmentally induced cracking tends to be more distributed in nature. Guse and Hilsdorf (1997) found that surface cracking is more likely to occur in high strength concrete than in normal strength concrete, and showed that these cracks can substantially increase surface permeability, despite having minimal influence on mechanical behaviour. Wiens et al. (1997) and Jacobsen et al. (1997) observed that under certain conditions high strength concrete developed a significant number of finely distributed micro-cracks, which accelerated the penetration of de-icing salts and freeze-thaw damage. Fagerlund (1997) speculated that cracks facilitate increased water absorption, thereby further accelerating freeze-thaw damage. Yang et al. (2006) showed higher absorption rates for freeze-thaw damaged concrete due to the interconnected cracking network.

This paper describes a technique that is being used to quantify the role of cracking on water absorption. Testing methods like ASTM C1585-04, the standard test method for measurement of rate of absorption of water by hydraulic-cement concretes, assess absorption by an overall change in sample mass (McCarter et al., 2005; Rajabipour et al., 2005). The procedure described in this paper is based on using a change in X-ray transmission/attenuation to measure the time dependent movement of fluid in the region around the crack.

X-rays have been previously used to study cracking in building materials. For example, Landis et al. (2003) have used X-ray tomography to locate and image cracks. It should be noted that relatively small specimens were used to obtain sufficient resolution from the technique. Similar studies were performed by Lawler et al. (2001) on specimens under load. In each of the aforementioned studies X-ray was used to detect a difference in material density due to the presence of a void (or crack). More recently, X-ray tomography has become popular owing to a rise in 'desktop' X-ray units.

Other researchers have used the X-ray transmission/attenuation to study the change in material density that occurs as a result of water movements (Bentz et al., 2001; Bentz et al., 2000). Since then this approach has been used to assess moisture loss due to drying in wood specimens (Jensen et al., 2001), in unburned clay (de Place and Hansen, 2002) and in masonry units (Hansen et al., 2003). In each of the aforementioned approaches the movement of water was assessed by detecting a difference in absorbed photons that were 
transmitted through the sample and received at the detector before and after water movement. The studies that have followed show the value of this technique. Roels and Carmeliet (2006) used an elegant approach to describe radiography for ceramic brick and cracked cellular (foamed) materials. Sant and Weiss (2009) examined the variation associated with variations in the X-ray beam energy. Sant et al. (2010) and Pour-Ghaz et al. (2009) and Pour-Ghaz et al. (2011) examined fluid ingress from a sample surface and in saw cuts respectively using fluids with different surface tensions and viscosities. This aided in understanding the role of fluid type which has implications on its use for assessing the movement of solutions containing deicing salts (Spragg et al., 2011) and contrasting agents (Pourasee et al., 2011). Pease et al. $(2009,2011)$ examined fluid ingress in plain and fibre reinforced concrete using X-ray radiography and related the physical crack geometry with an 'effective crack' obtained from a fracture mechanics-based hinge model. Pourasee et al. (2011) used X-ray radiography to examine fluid movement at steel and fabric reinforcement in cementitious mortars. In addition to using X-rays, researchers have explored other technologies that may have a higher contrast than X-rays. For example, Zhang et al. (2010) and Trtika et al. (2011) used neutron radiography to assess fluid ingress at cracks in mortar and to assess fluid movement from water sources (lightweight aggregate and super absorbent polymers) in the concrete.

\section{Experimental program}

This paper describes work performed while the first author was on sabbatical at the Technical University of Denmark. During that time X-ray measurements were made on cracked concrete samples. Since the time these experiments were performed there have been several studies that have used a variety of X-ray imaging and analysis to assess fluid transport in concrete as mentioned in the previous paragraph. While the full image analysis approaches have clear benefits in terms of speed and efficiency, this paper describes the use of an earlier technique that used point by point analysis with a beam with a small spot size (diameter of approximately $1 \mathrm{~mm}$ ). While the authors believe full image analysis has great benefits, this paper illustrates a few important concepts using data from the earlier point by point studies. First, the paper provides a discussion on how integration time influences the variability of the measurement and suggests the use of different integration times for dry (sample before wetting began) and wet (sample after wetting began) samples as a method to reduce variability if testing times for the wet specimen are limited. Second, the paper discusses several of the experimental details associated with testing heterogeneous systems like concrete due to the relatively large size of the aggregates as compared with the thickness. The influence of local variations due to aggregate is not observed in mortar and paste testing. Third, this paper describes an approach to determine initial effective crack length based on water absorption in a concrete as it is rewet. 


\subsection{Mixture proportions and specimen preparation}

Two concrete mixtures were used in this investigation. Both concretes contained $65 \%$ aggregate consisting of equal proportions of granite aggregate and graded sand. The mixtures had a water to cement ratio (w/c) of 0.42 and were prepared with an ordinary Danish Portland cement. The primary difference between these mixtures was the maximum size of the aggregate (MSA) with one mixture containing aggregates with a MSA of $8 \mathrm{~mm}$ and the other mixture with a MSA of $16 \mathrm{~mm}$. In addition to these concretes, samples $(50 \mathrm{~mm} \times 100 \mathrm{~mm} \times 100 \mathrm{~mm})$ of the granite aggregate and samples of mortar (with proportions identical to that expected in the concrete minus the coarse aggregate) were tested.

The specimens were mixed using a 60 litre batch size in a conventional pan mixer. The aggregates, half the sand, water, cement, and remaining sand were added to the mixer. Mixing was performed for two minutes, the mixer was permitted to rest for two minutes and an additional minute of mixing was performed.

After mixing the concrete was placed in cylindrical forms for compression testing and cube forms for wedge splitting tests. The cylinders were $100 \mathrm{~mm}$ diameter and $200 \mathrm{~mm}$ tall. The wedge splitting specimens were made using $100 \mathrm{~mm}$ cubes that were cast using an insert to create a $33 \mathrm{~mm} \times 20 \mathrm{~mm}$ void (i.e. water or chloride solution reservoir) at the top of the specimen. Figure 1 shows a picture of the wedge splitting specimens used in this test. At an age of 1 day the cylindrical and wedge splitting specimens were demolded, labelled and stored in a lime saturated water bath at $20^{\circ} \mathrm{C}$. At an age of 14 days the cubes were cut in half using a wet diamond tipped saw to create the specimen that was $100 \mathrm{~mm}$ tall, $100 \mathrm{~mm}$ wide, and $50 \mathrm{~mm}$ thick. The notch was then cut in the specimen creating a notch that was $3 \mathrm{~mm}$ wide and $30 \mathrm{~mm}$ deep. After the notches were cut the specimens were placed in an oven at $50^{\circ} \mathrm{C}$ until the age of 21 days. It should be noted that oven drying has been reported to increase absorption in materials due to potential damage in the microstructure, however this study was intended to investigate the use of the measuring technique and oven drying enabled a uniform moisture content to be attained reasonably quickly.

At an age of 21 days the wedge splitting specimens were removed from the oven and half of the specimens were mechanically tested using the wedge splitting test geometry (Figure 1), (Ostergaard, 2003) while the other half of the specimens were left to be tested without the introduction of the crack. Loading was performed following the procedure similar to that outlined by Ostergaard (2003) with the crack mouth opening displacement being used to control the test. The crack mouth opening was permitted to increase to 0.4 $\mathrm{mm}$ before the load was slowly removed. Upon removal of the loading the crack mouth opening closed to $0.3 \mathrm{~mm}$ as shown in Figure 1(b). After mechanical testing the specimens were placed back in the oven at $50^{\circ} \mathrm{C}$ where they remained for an additional 35 days to enable them to achieve a uniform level of moisture throughout the specimen. 
Figure 1 (a) Typical wedge splitting specimen geometry (a line from a black marker is shown on the specimen below the saw-cut, this was used to align the specimen during testing) and (b) typical wedge splitting test loading and unloading diagram (CMOD measured 20 $\mathrm{mm}$ from the top of the specimen, every 50th data point is plotted) (see online version for colours)

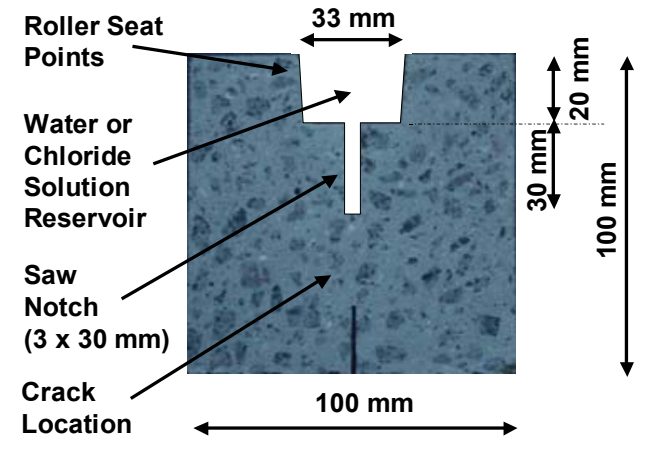

(a)

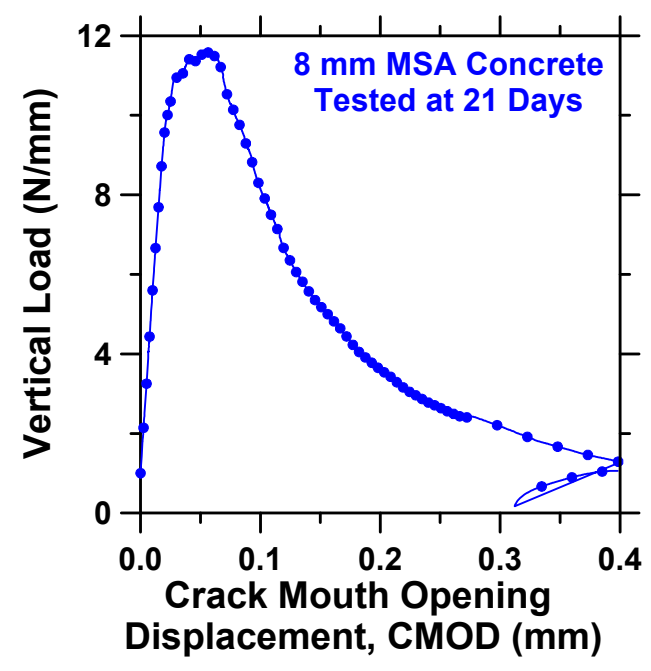

(b)

After removing the specimens from the oven and allowing them to cool, the specimens were partly wrapped using an epoxy impregnated composite fabric. Since the time of this work the researchers have found that for short term testing the use of an aluminium tape is sufficient to wrap the samples and is more convenient to work with. Before placing either the epoxy or fabric on the specimen a small piece of tape was placed along the crack (with an approximate size of $10 \mathrm{~mm} \times 50 \mathrm{~mm}$ ). This tape was placed on the specimens to avoid the risk of having the epoxy migrate into the crack. A single piece of fabric was used to cover both faces and the bottom of the specimen. This enabled a water reservoir to be created on the top of the specimen. After 24 hours the sides, faces, and bottom of the specimen were coated using a second layer of epoxy that was applied to the specimen leading the top and wedge exposed. Lego blocks were glued to the specimen to enable it to be positioned in the X-ray chamber in a repeatable position (Bentz et al., 2000) (Figure 2). 
Figure 2 (a) Typical illustration of the specimens in the X-ray chamber and (b) a close-up view of the specimen ready for water introduction (see online version for colours)

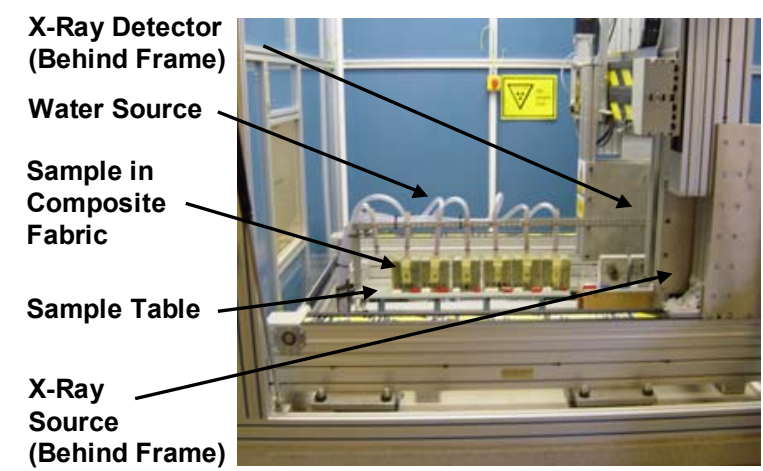

(a)

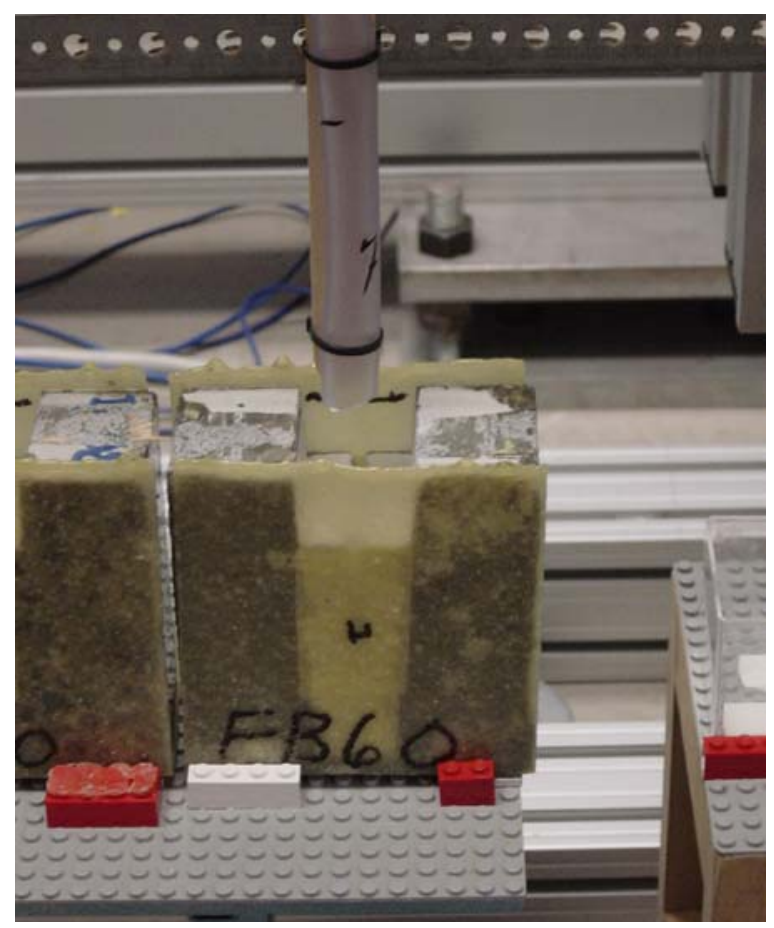

(b)

At an age of 28 days the compressive strength was tested in accordance with ASTM C-39 (compressive strength of cylindrical concrete specimens). Results of the compressive strength tests indicated that the specimens with the $16 \mathrm{~mm} \mathrm{MSA}$ had a 28 day compressive strength of $38 \mathrm{MPa}$ with a standard deviation of $3.2 \mathrm{MPa}$ while the concrete with a MSA of $8 \mathrm{~mm}$ had a 28 day compressive strength of $42 \mathrm{MPa}$ with a standard deviation of 2.9 MPa. The air contents of the concrete were measured in accordance with ASTM 173 and were to be $0.8 \%$ and $0.5 \%$ for the concrete with the $8 \mathrm{~mm}$ and $16 \mathrm{~mm}$ respectively. 


\subsection{Measurement technique}

The specimens were tested in the GNI X-ray attenuation system located at the Technical University of Denmark (Hansen et al., 1999b). This system consists of an X-ray source placed at a specific distance from a detector in an environmentally controlled chamber. While this distance can be varied between the source and the detector, for the studies described in this paper the detector has been placed $400 \mathrm{~mm}$ from the source. By placing the concrete sample between the X-ray source and the detector the specimen prevents a portion of the transmitted X-ray from reaching the sample. The portion of the X-ray that interacts with the sample can be either absorbed or reflected (attenuated). As such the resulting X-ray spectrum that is measured when the sample is between the source and detector is substantially lower than the spectrum measured in free air (i.e. with no sample in place).

This study used the X-ray tube at an energy level of $75 \mathrm{keV}$ and a current of $15 \mu \mathrm{A}$. A collimated X-ray beam was passed through the specimen and a NaI detector was used to measure the photon count over 256 channels. This X-ray beam has a diameter of approximately $1 \mathrm{~mm}$ and can be moved using a programmable $\mathrm{x}-\mathrm{y}$ positioning table with a resolution of $\pm 0.1 \mathrm{~mm}$. Figure 2 illustrates the prepared sample before the addition of water in the testing chamber. It should be noted that the user has the ability to control the duration of time (i.e. count time) for the detector to collect the information at any point and this will be discussed later in the paper.

\section{Experimental procedures and results}

\subsection{Typical spectra}

Figure 3(a) illustrates the measured X-ray spectra that passed through open air, $50 \mathrm{~mm}$ of water, and $50 \mathrm{~mm}$ of concrete and was recorded at the detector (the figure shows values of concrete multiplied by a factor of 10). It can be observed that the spectrum that was measured in open air is substantially greater than water, and water has a spectrum that has a greater number of counts than the other materials tested in this study. While the information measured between channels 0 and 160 corresponds to the specimen between the source and the detector, the peak occurring between channel 170 and 256 (with a peak at approximately channel 200) is generated by an internal cobalt source that is used for system calibration and therefore this information is not shown. Figure 3(b) illustrates the measured spectra for mortar, concrete and aggregate. It can be seen that the aggregate had the highest attenuation while the mortar had the lowest. Concrete, being a composite of the mortar and aggregate was located in between the responses of the other two constituent.

It should be noted that for the sake of this investigation the total counts per second is used as a simple single parameter to assess the total counts that passed through the specimen at each point in the specimen and was captured by the detector. The term 'total counts' refers to the sum of counts that are measured over the first 160 channels. To ascertain the repeatability that may be expected for each material, a count time of two minutes was used for obtaining this data and fifteen points at random locations throughout the material. Table 1 provides a comparison of the mean X-ray counts and 
coefficient of variation for the materials tested in this study. It should be noted that the aggregate, mortar, paste, and water have a relatively low coefficient of variation presumably owing to the consistency of these materials from point to point. The variability increases as aggregate is added to the mixture and further the variability increases as the size of this aggregate is increased. This may be due in part to scattering; however, it is believed that this is largely due to local variations of the amount of aggregate at any point in these relatively thin samples.

Figure 3 (a) X-ray spectra measured at the detector in counts in air, water and concrete, and (b) in aggregate, concrete and mortar (see online version for colours)

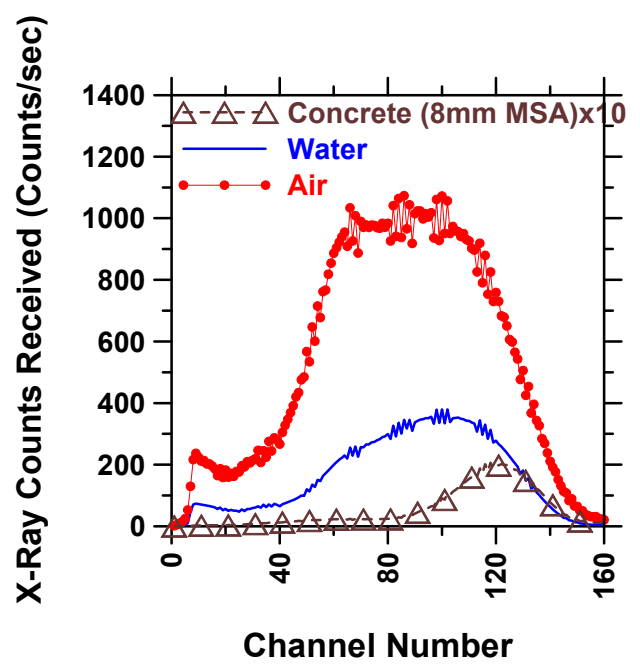

(a)

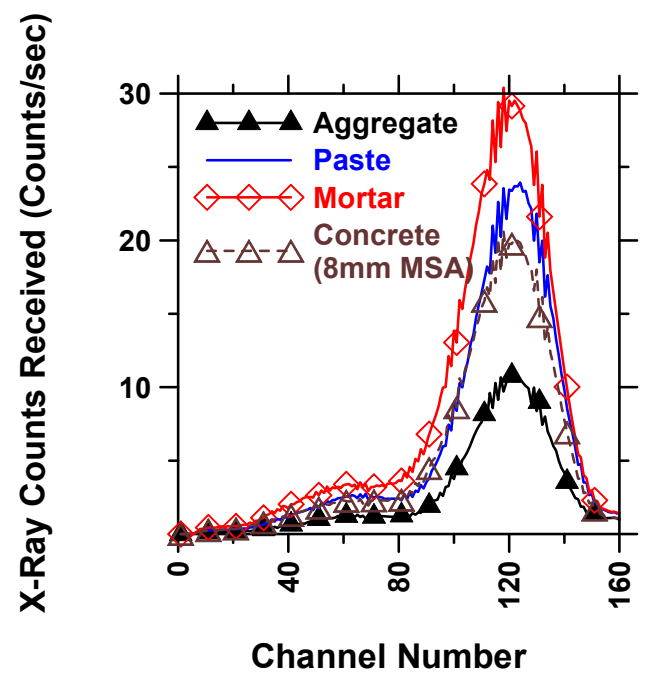

(b) 
Table 1 Comparison of the average counts received at the detector (per unit thickness and second) for different materials along with their coefficient of variation

\begin{tabular}{lcc}
\hline & \multicolumn{2}{c}{ X-ray counts received } \\
\cline { 2 - 3 } & Average counts $/ \mathrm{mm} / \mathrm{sec}$ & Coefficient of variation $\%$ \\
\hline Water & 531.6 & 0.05 \\
Paste & 19.3 & 0.85 \\
Mortar & 25.4 & 2.32 \\
Concrete* & 20.8 & 14.15 \\
Concrete** & 21.0 & 15.46 \\
\hline
\end{tabular}

Notes: Thickness of specimen: $50 \mathrm{~mm}$; count time: $2 \mathrm{~min}$; 15 points over and area of $40 \mathrm{~mm} \times 80 \mathrm{~mm} ; * 8 \mathrm{~mm}$ maximum aggregate size; * $16 \mathrm{~mm}$ maximum aggregate size

\subsection{Assessing the accuracy of measurement techniques}

The first parameter that needed to be determined before the testing protocol could be established was the relationship between measurement variation and the duration that the measurement was conducted over (i.e. count time). As expected the standard deviation of the X-ray count measurements reduces with a longer count time. To quantify the influence of count time, a series of tests were conducted measuring the coefficient of variation for a measurement taken seven times at five separate locations (approximately 1 $\mathrm{cm}$ apart) in the concrete with the $16 \mathrm{~mm}$ MSA for different count times $(2,5,10,20,30$, 60 and $90 \mathrm{sec}$ ). The results of this investigation are plotted in Figure 4 and a regression analysis was performed to determine the values shown in equation $(1)\left(R^{2}=0.99\right)$

$$
\sigma=3.14 \% \cdot \frac{1}{\sqrt{t}}
$$

where $t$ is the count time of the measurement as given in seconds. It should be noted that this describes the variability associated with a single measurement.

Since this study will investigate the influence of rewetting the specimen is necessary to discuss the variability that may be expected when two measurements are compared with one another. The fundamental idea behind comparing two measurements is that the addition of water will cause a change in the density (and a change in X-ray attenuation) at a particular point in a sample. Therefore, to assess how much water has entered the system the difference between the measured response of the dry and wet state is needed. As a result the error needs to be assessed considering the fact that both measurements have a certain degree of uncertainty. Equation (2) can be used to describe the coefficient of variation that results from two measurements.

$$
\sigma_{\text {Total }}=\sqrt{\left(\sigma_{\text {Dry }}^{2}+\sigma_{\text {Wet }}^{2}\right)}
$$

where the total coefficient of variation $\left(\sigma_{\text {Total }}\right)$ is related to the coefficient of variation in the dry specimen $\left(\sigma_{D r y}\right)$ and wet specimen $\left(\sigma_{W e t}\right)$.

At this point it is important to note that the rate of water absorption can be rapid in concrete. As a result there is a trade-off between the number of measurement points that can be used for each specimen and the count time that can be used at each point. 
Equation (2) was used to estimate the variation that can be expected in a system that is rewet using count times for the measurement in the wet condition that is different from the count time in the dry condition. It was observed that the variation in the measured response can be reduced by increasing the count time on the dry specimen as the duration of the test is less of a constraint before water is introduced. This allows the count time in the wet specimen to be substantially shorter.

A protocol was implemented in this work that used a 2 minute dry count time and a 15 second wet count time. This approach shows reasonable repeatability considering that the entire measurement can be performed on the dry specimen in 3 hours while the wet specimens could be measured in approximately 35 minutes (it should be noted that in addition to the count time there is time for the X-ray source and detector to be moved from one position to another). Using this protocol implies that a change in the X-ray attenuation ratio of more than $2 \%$ in the measured X-ray intensity could be safely assumed (97.5\% confidence) to signal a change in the moisture content of the system. A Monte Carlo simulation was used to confirm these results. While these times dramatically improve with full field image analysis there are times where this is still important as in the case of 'tiling' images together to improve the field of view (Pourasee et al., 2011; Pease et al., 2011).

Figure 4 Variability in measured X-ray count response as a function of time (see online version for colours)

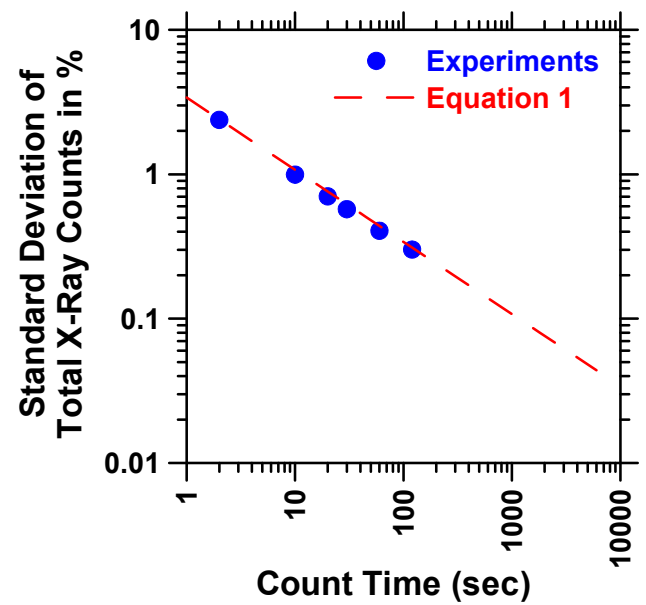

At the time of this study, it was noted that previous studies have simply used the difference between the number of counts in the dry and wet samples as a measure of water ingress. These tests were typically performed on mortars or pastes which can be considered fairly homogenous throughout the thickness of the specimen. Since these experiments were performed several research groups have more commonly using Beer's law directly relate the difference in counts to a thickness or volume of water at each location (Sant and Weiss, 2009; Sant et al., 2010; Pour-Ghaz et al., 2009; Pour-Ghaz et al., 2011; Spragg et al., 2011; Pourasee et al., 2011; Pease et al., 2009; Pease et al., 2011); however this points to a critical feature that has not been directly addressed, to the best of the authors knowledge, in the other studies. The materials used in this study are concretes, and are relatively thin as compared with the aggregate size. As such, they will 
have some degree of heterogeneity. Said another way, these materials will have more or less aggregate at each sampling location in the sample. This is a critical feature as water absorption of the mortar and aggregate can be quite different. Therefore if one just assesses the volume of water at each location this may not be able to be used to directly make comments on the degree of saturation or proportion of pore volume that is water filled at each location. For example, in this specific experiment, the aggregate has a long-term total change in mass (i.e. absorption capacity) due to absorption of approximately $0.06 \%$ while the mortar had a total long-term change in mass due to absorption of approximately $3.5 \%$. As a result it is essential to determine the amount of aggregate at a given location in the specimen.

The volume fraction of aggregate at each measurement point was estimated using a combination of Beer's law and a simple rule of mixtures approach (Rogasik et al., 1999) in equation (3)

$$
V_{\text {Aggregate }}=\frac{\mu_{\text {Mortar }}-\mu_{\text {Concrete }}}{\mu_{\text {Mortar }}-\mu_{\text {Aggregate }}} \cdot 100 \%
$$

where $\mu_{\text {Concrete }}$ is the 'measured' X-ray attenuation in the concrete, $\mu_{\text {Aggregate }}$ is the X-ray attenuation for a sample of pure aggregate, $\mu_{\text {Mortar }}$ is the X-ray attenuation for a sample of pure mortar, and $V_{\text {Aggregate }}$ is the volume fraction of the aggregate at each section of the sample that the X-ray was passing through. The 'measured' X-ray attenuation coefficient was calculated from experiments on the dry sample (since longer count times were used) using the measured sample thickness. To ascertain the applicability of this approach a series of ten measurements were taken in a specimen. This specimen later sectioned and examined under a microscope trying to align the locations of microscopic investigation with where the X-ray attenuation measurements were made. The physically observed aggregate fraction was found to correlate reasonably well with the predictions from equation (3). Further, the total average volume fraction of aggregate was computed for each specimen and found to be similar to that that would be expected from the mixture proportions.

The overwhelming majority of the water absorption (ABS) occurs in the mortar phase of the concrete. As a result, a normalised version of the change in X-ray attenuation (ABS) was used to assess the moisture ingress using the aggregate volume from equation (3). Equation (4) illustrates how ABS was computed.

$$
A B S=\frac{\mu_{\text {Concrete-Dry }}-\mu_{\text {Concrete-Wet }}}{\mu_{\text {Concrete-Dry }}} \cdot \frac{1}{V_{\text {Aggregate }}} \cdot 100 \%
$$

It can be shown [using equation (2)] that when the value of ABS is less than $2 \%$ this corresponds to variations that can be expected to occur within standard measurement variations (for $97.5 \%$ confidence) on a dry specimen. It was also observed that a value of ABS that is greater than $10 \%$ corresponds to a degree of saturation of over $95 \%$ for the mortar.

X-ray attenuation measurements were performed on the wedge splitting specimen shown in Figure 5. The grid that the X-ray attenuation was measured over is also shown in Figure 5. The X-ray attenuation measurements were begun on a column of points directly below the crack $(\mathrm{x}=0, \mathrm{y}=0,-4,-8,-12,-16,-24,-32,-40 \mathrm{~mm})$. After measuring the column below crack, the X-ray attenuation was measured in rows of points 
beginning at the top of the grid $(\mathrm{y}=8 \mathrm{~mm})$ and working across the specimens $(\mathrm{x}=-40$, $-32,-24,-16,-8,-4,0,4,8,16,24,32,40 \mathrm{~mm})$. These measurements were performed along horizontal rows at $(\mathrm{y}=8,0,-8,-16,-24,-32,-40 \mathrm{~mm})$. This entire grid consisted of a matrix of 98 measurements. The time discussed in the measurement interpretation refers to the time that the measurements were begun and the entire matrix required approximately 35 minutes to complete the actual measurements and entire matrix was programmed to a 40 minute schedule.

Figure 5 An illustration of the specimen geometry and X-ray positions (see online version for colours)

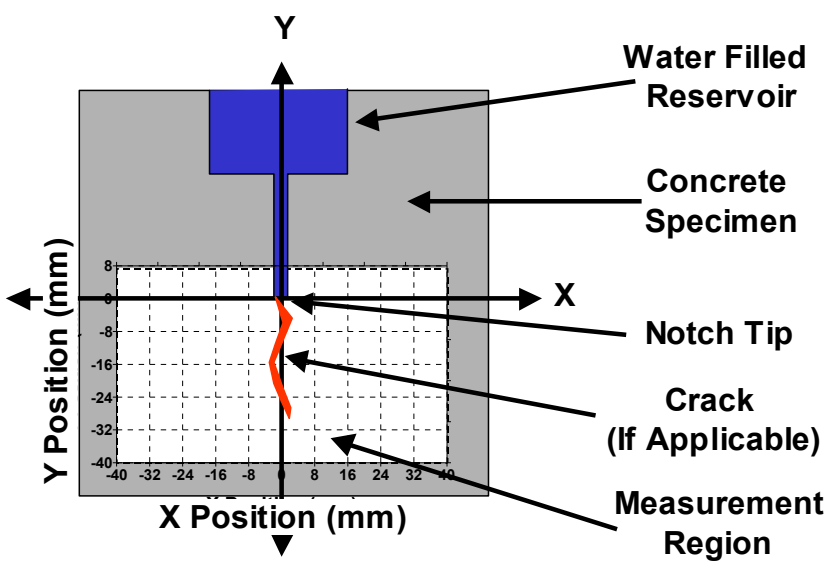

\section{Discussion of results}

Figure 6 illustrates the normalised change in X-ray attenuation (ABS from equation 4) for a concrete with a MSA of $8 \mathrm{~mm}$ at various times after the introduction of water. A typical concrete sample without a crack is shown on the left side of the diagram while the cracked concrete is shown on the right side. The contour lines in these graphs correspond to different levels of normalised difference in X-ray attenuation (ABS) with $2 \%$ being the minimal level of repeatable detection and $10 \%$ corresponding to saturation.

It is important to recall that the origin of this graph $(0,0)$ corresponds to the tip of the saw-cut that is filled with water (Figure 5). It can be noticed that in the specimens without the crack the moisture proceeds parallel to the vertical walls of the saw-cut and forms a hemisphere at the bottom of the saw-cut. This is similar to the predictions of Hall and Hoff (2002) for various absorption specimen geometries. Over time the diameter of the hemisphere at the bottom of the saw-cut increases.

The cracked specimen however shows that the water extends further below the bottom of the saw-cut. This illustrates that the crack (which is wide at the top and tapered) has a large portion of the crack that is presumably acting like a free surface. The water penetration front appears to have a larger vertical front over a larger portion of the specimen while at the same time progressing toward the bottom of the specimen. 
Figure 6 Typical plots of the normalised difference in attenuation (ABS) around the tip of the sawcut $(0,0)$ for (a) uncracked and (b) cracked specimens $(8 \mathrm{~mm}$ MSA) (see online version for colours)
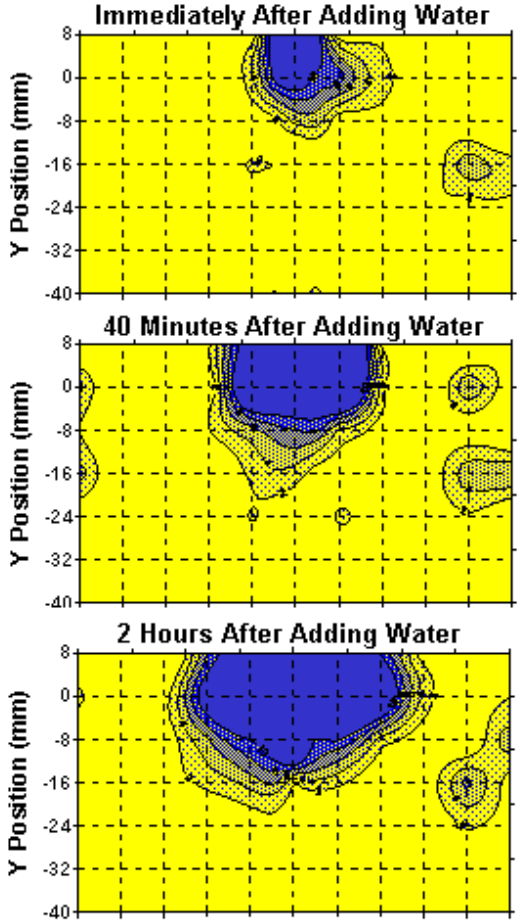

6 Hours After Adding Water

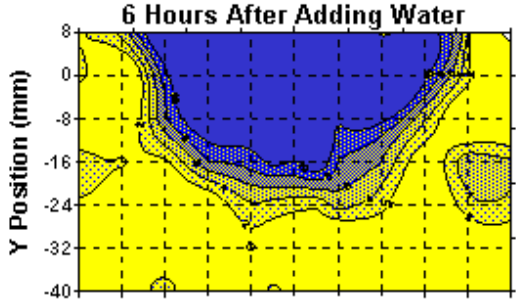

12 Hours After Adding Water

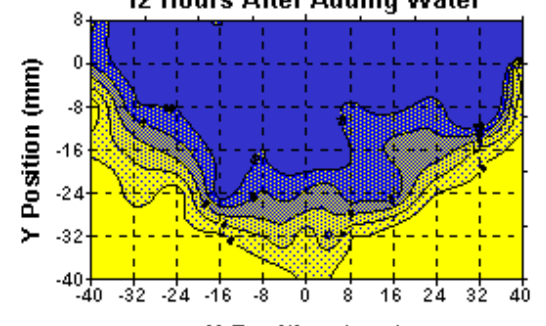

$\mathrm{X}$ Position (mm)
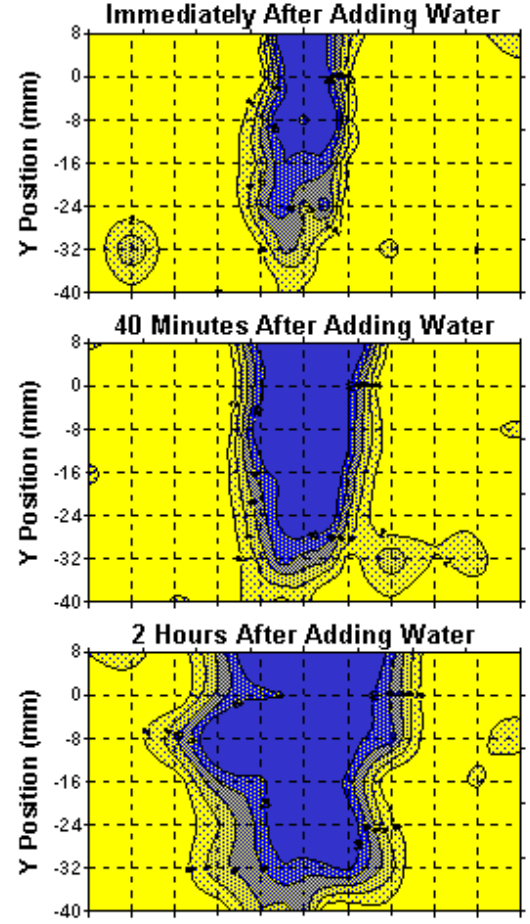

6 Hours After Adding Water

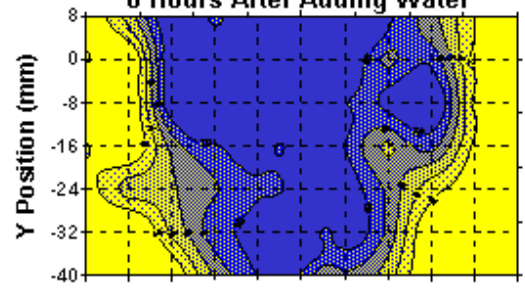

12 Hours After Adding Water

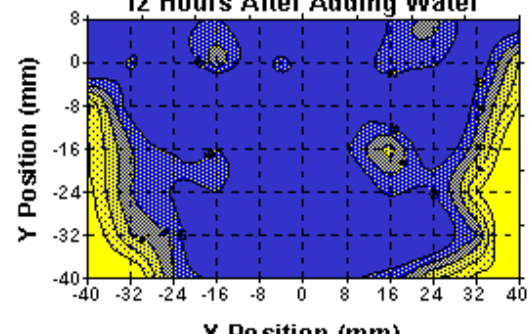

$X$ Position (mm)

Normalized Difference in X-Ray Absorption

\begin{tabular}{|l|l|l|l|l|l|}
\hline & & & & & \\
\hline$<2 \%$ & 2 to $4 \%$ & 4 to $6 \%$ & 6 to $8 \%$ & 8 to $10 \%$ & $>10 \%$ \\
\hline
\end{tabular}

(a)

(b) 
In addition to looking at the qualitative differences in the graphs it is possible to use these graphs to assess quantitative information about the specimens that were tested. For example the volume of the paste that was rewet could be determined by computing the area represented by each contour line. In addition the perimeter of the contour lines could be used to determine the 'saturation perimeter' at each age. The saturation perimeter may be used to estimate the initial geometry of the problem (if it were unknown) and can therefore be used to estimate a crack size to estimate how much of the crack surface acts as a free surface.

Figure 7 illustrates a plot of the saturation perimeter at different times after water addition. (The time corresponds to the time at which the measurement of the grid began). The initial perimeter of the crack (i.e. y-intercept) can be estimated from these graphs. As one may expect, the perimeter for the cracked specimens is higher than the uncracked specimens. The uncracked specimens have a perimeter that is only slightly higher than the $19 \mathrm{~mm}$ saw-cut surface perimeter ( $8 \mathrm{~mm}$ side $+3 \mathrm{~mm}$ bottom $+8 \mathrm{~mm}$ side) that would be expected from the initial saw-cut geometry. This is likely due to the assumption that the initial measure corresponds to the time of water addition when in reality it is anywhere between the time of water addition and 35 minutes after water addition. It can be seen that the perimeter increases approximately in proportion with the square-root of time. The cracked specimens have a y-intercept of $54 \mathrm{~mm}$ for the specimen with the $8 \mathrm{~mm}$ MSA and $69 \mathrm{~mm}$ for the specimen with the $16 \mathrm{~mm}$ MSA. This would imply that the concrete with the $8 \mathrm{~mm}$ MSA would have a crack of approximately $20 \mathrm{~mm}$ depth that acts as a free surface while the $16 \mathrm{~mm}$ MSA would be approximately $26 \mathrm{~mm}$. This would be consistent with the idea that a more coarse grained materials having a larger hysteresis on unloading due to interparticle friction as the crack closes. This may imply that the crack would be more likely to remain slightly open after unloading. Also a difference in slope (i.e. sorptivity) of the uncracked and cracked specimens can be observed, according to expectations, cracking increases the sorptivity of the specimens.

Figure 7 Typical plots of the perimeter of the water saturation area in the wedge splitting test (see online version for colours)

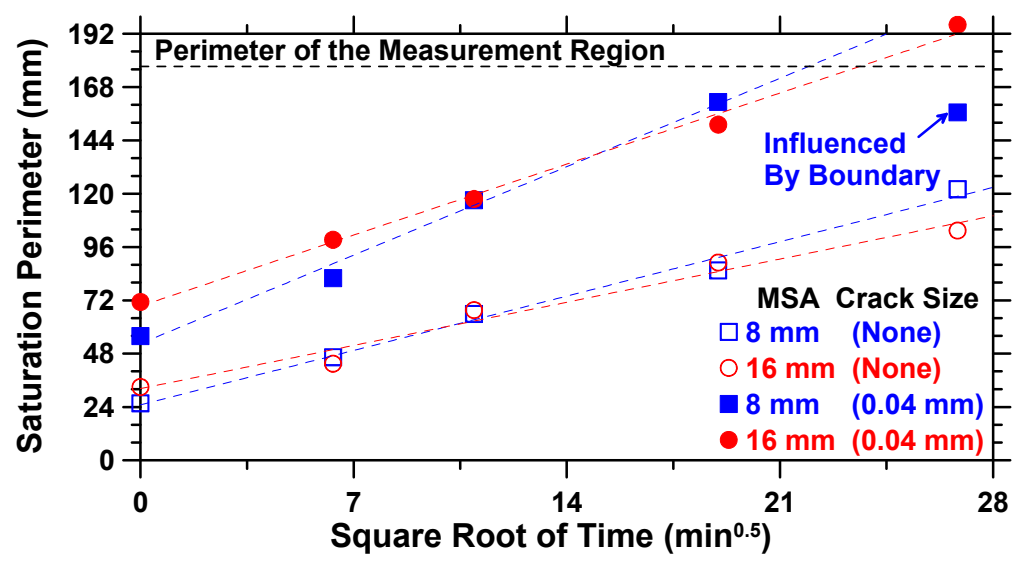




\section{Summary and conclusions}

This paper has illustrated a procedure in which the difference in X-ray attenuation between a dry concrete and a rewet concrete can be used to assess fluid transport (absorption) in heterogenous concrete. A procedure was developed to estimate the local coarse aggregate volume using a combination of Beer's law and the law of mixtures. This is important since in many thin elements the volume of the aggregate can vary considerably at each location in the sample. The change in attenuation during wetting was used to assess the moisture absorption in the mortar part of the specimens. While more recent work has shown the power of using full image analysis this work shows principles for improving resolution by using different drying and wetting times when measurement time is a limiting step. This can be important for point measurements as well as when image tiling is used. A wedge splitting test was used to introduce a crack in a specimen. After the crack was introduced, the specimen was dried to achieve a uniform moisture condition throughout the specimen. The specimen was then tested using a local 'spot' to assess the portion of the X-ray beam that was transmitted through the specimen. The change in attenuation was measured on a grid of points throughout the specimen. The uncracked specimen was observed to have an elliptical water absorption front centred at the bottom of the saw-cut, while the cracked specimen $(0.4 \mathrm{~mm}$ initial crack width) appeared to indicate that a large portion of the crack face essentially acted as a free surface. The X-ray attenuation technique is quite powerful and should make it possible to investigate water absorption in cracked concretes, in elements with varying moisture distribution before rewetting, and in elements with complicated geometries.

\section{Acknowledgements}

The authors gratefully acknowledge support from the Knud Højgaard Foundation, Denmark and the National Science Foundation (Grant No. 0134272) for the financial support of J. Weiss during his stay in 2004 at the Technical University of Denmark. Any opinions, findings, and conclusions or recommendations expressed in this material are those of the author(s) and do not necessarily reflect the views of the National Science Foundation.

\section{References}

Aldea, C.M., Shah, S.P. and Karr, A.F. (1999) 'Permeability of cracked concrete', Materials and Structures, Vol. 32, No. 5, pp.370-376.

Bentz, D.P. and Hansen, K.K. (2000) 'Preliminary observations of water movement in cement pastes during curing using X-ray absorption', Cement and Concrete Research, Vol. 30, No. 7, pp.1157-1168.

Bentz, D.P., Hansen, K.K., Madsen, H.D., Vallee, F. and Griesel, E.J. (2001) 'Drying/hydration in cements pastes during curing', Materials and Structures, Vol. 34, No. 243, pp.557-565.

de Place, H.E.J., Hansen, K.K. (2002) 'Unfired clay bricks - moisture properties and compressive strength', Proceedings of the 6th Symposium on Building Physics in the Nordic Countries, Trondheim, Norway.

Edvardson, C. (1999) 'Water permeability and autogenous healing of cracks in concrete', $A C I$ Materials Journal, Vol. 96, No. 4, pp.448-455. 
Fagerlund, G. (1997) 'On the service life of concrete exposed to frost action, freeze and thaw durability of concrete', in Marchand, J., Pigeon, M. and Setzer, M. (Eds.): E\&FN Spon, pp.24-41.

Guse, U. and Hisdorf, K. (1997) 'Surface cracking of high-strength concrete - reduction by optimization of curing', in Persson, B. and Fagerlund, G. (Eds.): Self-Desiccation and Its Importance in Concrete Tech., pp.239-249, Lund University, Lund, Sweden.

Hall, C. and Hoff, W.D. (2002) Water-Transport in Brick, Stone and Concrete, Spon Press, London UK.

Hansen, E.J.P., Ekman, T. and Hansen, K.K. (1999a) 'Durability of cracked fiber reinforced concrete structures exposed to chlorides', Proceedings of the 8th International Conference on the Durability of Building Materials and Components, Vancouver, Canada, 30 May to 3 June, 1999, pp.280-289.

Hansen, K.K., Jensen, S.K., Gerward, L. and Singh, K. (1999b) 'Dual-energy X-ray absorptiometry for the simultaneous determination of density and moisture content in porous structural materials', Proc. of the 5th Symposium on Building Physics in the Nordic Countries, Gothenburg, Sweden, Vol. 1, pp.281-288.

Hansen, K.K., Munch, T.A., Thorsen, P.S., Villumsen, C. and Bentzon, L.C. (2003) 'Moisture movements in render on brick wall', Proceedings of the 2nd Int. Building Physics Conference, Leuven, Belgium.

Hearn, N. (1998) 'Self-sealing, autogenous healing and continued hydration: what is the difference', Materials and Structures, Vol. 31, No. 8, pp.563-567.

Hearn, N. (1999) 'Effect of shrinkage and load-induced cracking on water permeability of concrete', ACI Materials Journal, March-April, Vol. 96, No. 2, pp.234-240.

Jacobsen, S., Marchand, J. and Boisvert, L. (1997) 'Effect of cracking and healing on chloride transport in OPC concrete', Cement and Concrete Research, Vol. 26, No. 6, p.869.

Jensen, S.K., Damkilde, L. and Krabbenhøft, K. (2001) 'Non-destructive assessment and FEM simultations of moisture profiles in Sitka spruce (Picea Sitchensis) during drying', Proceedings of Cost Action E15 Workshop on Timber Drying, Helsinki, 11-12 June.

Küter, A., Geiker, M.R., Olesen, J.F. and Stang, H. (2005) 'Chloride ingress in concrete cracks under cyclic loading', 3rd International Conference on Construction Materials 'CONMAT $05^{\prime}$, Vancouver, Canada.

Landis, E., Nagy, E.N. and Keane, D.T. (2003) 'Microstructure and fracture in three dimensions', Engineering Fracture Mechanics, Vol. 70, Nos. 7-8, pp.911-925.

Lawler, J.S., Keane, D.T. and Shah, S.P. (2001) 'Measuring three-dimensional damage in concrete under compression', ACI Materials Journal, Vol. 98, No. 6, pp.465-475.

McCarter, W.J., Chrisp, T.M., Starrs, G., Basheer, P.A.M. and Blewett, J. (2005) 'Field monitoring of cover-zone concrete', Cem. and Conc. Composites, Vol. 27, Nos. 7-8, pp.809-817.

Ostergaard, L. (2003) Early-Age Fracture Mechanics and Cracking of Concrete: Experiments and Modeling, PhD Thesis, Technical University of Denmark.

Pease, B.J., Couch, J.B., Geiker, M.R., Stang, H. and Weiss, W.J. (2009) 'Quantifying moisture movement in cracked concrete using X-ray absorption', International RILEM Conference on Concrete Durability and Service Life Planning 'ConcreteLife '09', Haifa, Israel.

Pease, B.J., Geiker, M., Stang, H. and Weiss, J. (2011) 'The design of an instrumented rebar for assessment of corrosion in cracked concrete', Mater. Struct., Vol. 44, No. 7, pp.1259-1271.

Pourasee, A., Peled, A. and Weiss, J. (2011) 'Fluid transport in cracked fabric-reinforced-cementbased composites', J. Mater. Civ. Eng., Vol. 23, No. 8, pp.1227-1238 [online] http://dx.doi.org/10.1061/(ASCE)MT.1943-5533.0000289.

Pour-Ghaz, M., Castro, J.E., Rajabipour, F. and Weiss, W.J. (2009) 'Measurement and modeling fluid transport in cracked concrete', International RILEM Conference on Concrete Durability and Service Life Planning, ConcreteLife '09', Haifa, Israel. 
Pour-Ghaz, M., Rajabipour, F., Couch, J.B. and Weiss, J. (2011) Numerical and Experimental Assessment of Unsaturated Fluid Transport in Saw-Cut (Notched) Concrete Elements, ACI Special Publication, Farmington Hills, Michigan.

Rajabipour, F., Weiss, W.J., Shane, J.D., Mason, T.O. and Shah, S.P. (2005) 'Procedure to interpret electrical conductivity measurements during rewetting', Journal of Materials in Civil Engineering, Vol. 17, No. 5, pp.586-594.

Roels, S. and Carmeliet, J. (2006) 'Analysis of moisture flow in porous materials using microfocus X-ray radiography', International Journal of Heat and Mass Transfer, Vol. 49, Nos. 25-26, pp.4762-4772.

Rogasik, H., Crawford, J.W., Wendroth, O., Young, I.M., Joschko, M. and Ritz, K. (1999) 'Discrimination of soil phases by dual energy X-ray tomography', Soil Science Society of America Journal, Vol. 63, pp.741-751.

Samaha, H.R. and Hover, K.C. (1992) 'Influence of microcracking on the mass transport properties of concrete', ACI Materials Journal, Vol. 89, No. 4, pp.416-424.

Sant, G. and Weiss, W.J. (2009) 'Using X-ray absorption to assess moisture movement in cementbased materials', Journal of ASTM International, July, Vol. 6, No. 9, p.15.

Sant, G., Eberhardt, A., Bentz, D. and Weiss, J. (2010) 'The influence of shrinkage-reducing admixtures (SRAs) on moisture absorption in cementitious materials at early-ages', Journal of Materials in Civil Engineering, March, Vol. 22, No. 3, pp.277-286.

Spragg, R., Castro, J., Li, W., Pour-Ghaz, M., Huang, P. and Weiss, W.J. (2011) 'Wetting and drying of concrete in the presence of deicing salt solutions', Cement and Concrete Composites, May, Vol. 33, No. 5, pp.535-542.

Trtika, P., Münch, B., Weiss, W.J., Kaestner, A., Jerjen, I., Josic, L., Lehmann, E. and Lura, P. (2011) 'Release of internal curing water from lightweight aggregates in cement paste investigated by neutron and X-ray tomography', Nuclear Instruments and Methods in Physics Research, Section A, Vol. 651, No. 1, pp.244-249, 10.1016/j.nima.2011.02.012.

Wang, K., Jansen, D.C., Shah, S.P., and Karr, A.F. (1997) 'Permeability study of cracked concrete', Cement and Concrete Research, Vol. 27, No. 3, pp.381-393.

Wiens, U., Meng, B., Schroeder, P. and Schiessl, P. (1997) 'Micro-cracking in high-performance concrete-from model to the effect on concrete properties', in Persson, B. and Fagerlund, G. (Eds.): Self-Desiccation and Its Importance in Concrete Technology, pp.193-208, Lund University, Lund, Sweden.

Yang, Z., Weiss, W.J. and Olek, J. (2006) 'Water transport in concrete damaged by tensile loading and freeze-thaw cycling', Journal of Materials in Civil Engineering, 1 June, Vol. 18, No. 3, pp.424-434.

Yang, Z., Weiss, W.J. and Olek, J. (2007) 'Water absorption in partially saturated fractured concrete', Workshop on Transport Mechanisms in Cracked Concrete, RILEM Week, Ghent, Belgium, pp.27-34.

Zhang, P., Wittmann, F.H., Zhao, T. and Lehmann, E.H. (2010) 'Neutron imaging of water penetration into cracked steel reinforced concrete', Physica B: Condensed Matter, Vol. 405, No. 7, pp.1866-1871. 